Because of concerns about the safety of using viruses and their limited capacity to carry inserted genes other approaches are being evaluated. These include the use of liposomes, direct injection of DNA into growing muscle without a viral helper, and preparation of human minichromosomes, which could contain all of the surrounding sequences activating and suppressing the gene in a physiologically controlled fashion. If modified, highly efficient, and safe techniques for gene delivery and targeting are devised (which might involve injection or ingestion) this could become an enabling technology of great importance not only for genetic disease but also for prevention. For example, delivering the gene for the low density lipoprotein receptor to the liver, thereby lowering blood glucose concentration, has been seen in terms of treatment of inherited hypercholesterolaemia but may equally be valuable in acquired or idiopathic cases.

The overall picture is, therefore, hopeful. Gene therapy will become the treatment of choice for several single gene disorders during the coming decade, particularly where the affected organs are accessible. It may become a method of targeting lethal genes to cancer cells and may join surgery, chemotherapy, and radiotherapy as routine treatments for cancer. Perhaps most importantly, the techniques of gene therapy could represent a general method for the delivery of gene products into many human tissues in a specific and controllable fashion, introducing a new modality into safe drug delivery. It won't happen immediately, but progress is occurring faster than anyone would have predicted even a decade ago.

KAY DAVIES Professor

MRC Clinical Sciences Centre,

Royal Postgraduate Medical School,

London W12 0NN

OB WILLIAMSON

Professor

Department of Biochemistry and Medical Genetics,

St Mary's Hospital Medical School,

London W2 1 PG

Anderson WF. Human gene therapy. Science 1992;256:808-13.

Clothier C. Report of the Committee on the Ethics of Gene Therapy. London: HMSO, 1992.

Weatherall DJ. Basic molecular and cell biology. 2nd ed. London: BMJ Publishing Group, 1992.

4 Miller AD. Human gene therapy comes of age. Nature 1992;357:455-60.

Dorin JR, Dickinson P, Alton EW, Smith SN, Geddes DM, Stevenson BJ. Cystic fibrosis in the mouse by targeted insertional mutagenesis. Nature 1992,359:211-5.

Colledge WH, Ratcliff R, Foster D, Williamson R, Evans MJ. Cystic fibrosis mouse with intestina obstruction. Lancet 1992;340:680.

Snouwaert JN, Brigman KK, I atour AM, Malouf NN, Boucher RC, Smithies O, et al. An animal model for cystic fibrosis made by gene targeting. Science 1992;257:1083-8.

Heyde SC, Gill DR, Higgins CF, Trezise AEO, MacVinish LJ, Cuthbert AW, et al. Correction of the ion transference defect in cystic fibrosis transgenic mice by gene therapy. Nature $1993 ; 362: 250-5$

9 Coutelle C, Caplen N, Hart S, Huxley C, Williamson R. Gene therapy for cystic fibrosis. Arch Dis Child 1993;68:437-43.

10 Gutierrez AA, Lemoine NR, Sikora K. Gene therapy for cancer. Lancet 1992;339:715-2

\title{
Long term risks after attempted suicide
}

\section{Identifying risk factors should help to reduce subsequent suicide}

The Health of the Nation's targets for mental health include two on preventing suicide: to reduce the suicide rate by $15 \%$ in the general population and by $33 \%$ in severely mentally ill people.' Health care professionals' reactions to this initiative have been mixed-some welcoming it, others lacking enthusiasm and even dismissing it. Two papers in this week's journal contribute to the topic (p 1637,2 p 1641 ${ }^{3}$ ). Both examine the long term risk of suicide in people who have been admitted to hospital for attempted suicide; they provide valuable further evidence concerning the greatly increased vulnerability of such patients to suicide as well as other causes of premature death. Importantly, they focus on adolescents and young adults: it is among young adult men that suicide rates have risen recently.

The Danish study reports a 10 year follow up of all patients admitted in 1980 to a poisoning treatment centre for attempted suicide. $^{2}$ Although case note data were obtained retrospectively, the reliability of follow up benefited considerably from access to national registers concerned with population statistics and causes of death. The findings show that such patients have a high risk of premature death from both unnatural and natural causes compared with the general population. Rates of suicide and deaths from uncertain causes are increased by factors of 30 and 60 respectively. Such patients, especially substance misusers, are also at greatly increased risk of premature death from accidents. Deaths due to natural causes were also significantly increased and were commonly related to physical illness secondary to alcohol misuse, younger adults being at greater risk. Factors that were significantly associated with subsequent suicide were greater age, living alone, manic depressive illness, a history of more than two episodes of attempted suicide, and, surprisingly, not being treated in a respirator after the index attempt. Retrospective analysis also suggested that alcohol misuse may have been missed in some cases at the time of the index admission.

The case-control follow up study from the Regional Poisoning Treatment Centre in Edinburgh focused more specifically on adolescents and young adults aged 15 to 24 who had been admitted during 1968-85 and examines risk factors for subsequent suicides that occurred locally. ${ }^{3}$ Without a comprehensive population register it was not possible to decide the completeness of follow up information, but the findings are both convincing and important. Factors significantly associated with subsequent suicide were social class V, unemployment, previous inpatient psychiatric treatment, substance misuse, personality disorder, and previous attempted suicide. Of these, misuse of alcohol or drugs and previous inpatient psychiatric treatment remained significant independent risk factors after multifactorial analysis. The authors emphasise the importance in suicide prevention of developing a well coordinated service for substance misuse in young adults in parallel with a preventive programme aimed at early detection and education. The importance of these findings is underlined by evidence from elsewhere that younger people who commit suicide are less likely than others to make contact with services in the last weeks of their lives. ${ }^{4}$

Both follow up studies show the difficulties that we face in deciding exactly how to use risk factors in routine clinical situations, given their low specificity and sensitivity. The Danish authors go so far as to claim that, although high risk factors can be identified, a high risk strategy is not suitable for preventing suicide. This view should be challenged. Despite their limitations risk factors must surely be of value to a doctor who has the unenviable task of trying to predict the short term 
risk of suicide, relevant to the next few days or even less. They are at least an invaluable double check on individual clinical assessment. Their presence when risk is judged otherwise to be minimal should make doctors query their original assessment. Surely, for example, we would expect a house physician to think twice, and yet again, before acceding to a request for rapid discharge by an elderly man who has been admitted after a deliberate overdose, especially if he has been misusing alcohol, is depressed, has important physical illness, and has recently suffered a major loss such as bereavement.

Given the limitations of predicting risk factors, how can we help the doctor to assess short term risk? This is central to day to day clinical work and by no means esoteric. Risk factors derived from well conducted follow up studies such as those already described are, of course, important. But clinical audit may help to identify a new range of risk factors by focusing on day to day issues such as problems with behaviour and relationships, which relate more immediately to short term risk. ${ }^{5}$ Clinical audit should also help to define more clearly the clinical techniques and skills relevant to assessing and managing the risk of suicide. Audit should thus ensure that the right thing is done $^{6}$ and has the potential to reveal anomalies and gaps in clinical practice which, if remedied, should help us meet the targets we have been set. We might then approach these with confidence and enthusiasm.

GETHIN MORGAN

Department of Mental Health, Professor of mental health

University of Bristol,

Bristol BS2 8DZ
1 Department of Health. The health of the nation: strategy for health in England. London: HMSO, 1992 (Cm 1986.)
2 Nordentoft M, Breum L, Munck LK, Nordestgaard AG, Hunding A, Bjaeldager PAL. High mortality by natural and unnatural causes: a 10 year follow up study of patients admitted to mortality by natural and unnatural causes: a 10 year follow up study of
poisoning treatment centre after suicide attempts. $B M$ I 1993;306:1637-41.
3 Hawton K, Fagg J, Platt G, Hawkins M. Factors associated with suicide after parasuicide in young people. $B M \mathcal{F} 1993 ; 306: 1641-4$
4 Vassilas CA, Morgan HG. General practitioner contact with suicides. $B M Y$ (in press).
5 Morgan HG, Priest P. Suicide and other unexpected deaths amongst psychiatric inpatients. The Bristol confidential inquiry. Br f Psychiatry 1991;158:368-74

6 Smith R. Audit and research. BMF 1992;305:905-6.

\section{Management at the MRC}

\section{Old fashioned and in need of reform}

The main thrust of the government's reforms of the NHS was to push management responsibility downwards so that hospitals, units within them, general practices, and community units could be rewarded if they performed well-or punished if they did badly. The aim was to get away from the top down management style of the monolithic NHS. William Waldegrave, who was secretary of state for health on the day the changes were introduced, said at the time: "We've battered away over the past 40 years trying to improve outcomes in essentially a top down way. And when things weren't going well we set up another tier of administration or took one away or changed its boundaries. Ultimately, you can't run an organisation employing nearly a million people like that. You have to give the people down the line the power to improve it themselves."

Readers will have their own ideas on whether these reforms have been successful, but in management and economic terms they make perfect sense. Planned economies-like those that operated in the Eastern bloc-are doomed to failure because those doing the planning can never have enough information. Huge companies-like General Motors, IBM, and ICI-have to give real power to those close to customers and make sure that their central organisations add something to the company or they collapse. All of these companies have gone too slowly with the process and are in trouble as a result. Even in small organisations the management trend is to flatten the structure, break down departmental divisions, and reward those who show real initiative and ability to learn and change: otherwise, the organisation fails to adapt quickly enough to the rapidly changing world and is destroyed by its competitors.

The most rapidly changing world of all is that of science and technology, and managing a community of scientists and researchers is one of the most difficult challenges in management. The challenge must be to give power to those close to the research while making sure that they operate within a strategy that will bring benefits to those paying for the research. And the failure of the government's strategy for science, which was introduced last month, is that it stayed with the traditional top down management structure and did nothing to shift power downwards. ${ }^{2}$ Ironically, the strategy was produced by the same minister, William Waldegrave, who was so clear on the necessity for the NHS reforms to give power to those close to the patients.

The measure of that failure is illustrated by two papers in this week's journal, which look at the management structure of the Medical Research Council (MRC) from the point of view of the directors of its smaller units. ${ }^{45}$ One of the authors, Roy Gillett, is a researcher who works in one of the units and had to take on most of the management load within the unit. To help him develop his skills he took a master of business administration degree, and his project was to survey the MRC's management of small units. All of the unit directors cooperated with the study, but the central MRC bureaucracy was unhelpful. This in itself is a bad sign: organisations that want to move forward welcome opportunities for critical examination.

The picture that emerges is that the unit directors feel impeded rather than aided by the central MRC bureaucracy. One in eight of the MRC staff works in the head office, which is positioned in an expensive part of central London and does no research, yet the directors feel that they must do most of the managing of the units themselves. Head office staff are rarely seen in the units, apart from during the peer review process, which is so prolonged that it manages to blight almost half of the units' time. The centre is seen by the unit directors as bureaucratic and dictatorial, while they are operating a management style that is oriented towards particular tasks. A survey of the middle managers at the MRC's head office described the organisation as "introspective, secretive, paternalistic, bureaucratic, compartmentalised, lacking a team spirit, perfectionist, slow and amateur in approach to managing." 4

The authors of the two papers published this week and most of the unit directors would like to see profound changes in the management style of the MRC. The centre should be shrunk and the culture of what remains revitalised. Units should be aided in their management tasks by general managers along the lines of those seen in the best general 